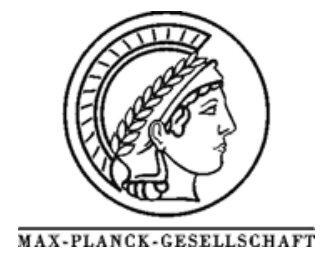

\title{
Ru nanoparticles stabilized by organosilane fragments: Influence of the initial Si/Ru ratio and thermal stability
}

\author{
K. Pelzer ${ }^{1, *}$, J.P. Candy ${ }^{2}$, G. Bergeret ${ }^{3}$, J.M. Basset $^{2}$ \\ ${ }^{1}$ Department of Inorganic Chemistry, Fritz-Haber-Institute of the MPG, Faradayweg 4-6, 14195 Berlin, Germany \\ ${ }^{2}$ LCOMS, UMR CNRS-CPE 9986, 43 boulevard du 11 novembre 1918, 69616 Villeurbanne, France \\ ${ }^{3}$ I.R.C., 2 avenue A. Einstein, 69626 Villeurbanne, France \\ * Corresponding author: e-mail pelzer@fhi-berlin.mpg.de,
}

Received 1st August 2006 / Received in final form 4 October 2006 Published online 24 May 2007.

\begin{abstract}
The decomposition of the organometallic ruthenium precursor [Ru(COD)(COT)] (COD: 1,5-cyclooctadiene; COT: 1,3,5cyclooctatriene) in mild conditions $\left(20^{\circ} \mathrm{C}, 3\right.$ bar $\left.\mathrm{H}_{2}\right)$ in $n$-pentane leads, in the presence of octylsilane $\left(\mathrm{H}_{3} \mathrm{SiC}_{8} \mathrm{H}_{17}\right)$ to the formation of stable Ru nanoparticles with narrow size distribution. The solids obtained after washing and drying were fully characterized by elemental analysis, TEM with EDX, infra red measurements as well as solid state ${ }^{13} \mathrm{C} C P-M A S ~ N M R$ investigations. The influence of the initial octylsilane/Ru(COD)(COT) ratio ranging from 0.2 to 2.0 was studied. It was observed that the size of the nanoparticles decreases with the initial Si/Ru ratio. The thermal stability of these nanoparticles $(\mathrm{Si} / \mathrm{Ru}=1)$ was also studied and as expected the size of the particles drastically increases after treatment under $\mathrm{H} 2$ at $500{ }^{\circ} \mathrm{C}$, while surprisingly under neutral atmosphere, there is only a slight increase.
\end{abstract}

\section{Introduction}

Nanoparticles of various metals e.g. Au, Pd, Pt, Ru. with diameters in the nanometer range are currently prepared, using various organic compounds as stabilizers [111]. As example, ruthenium nanoparticles of about $2 \mathrm{~nm}$ were prepared by the decomposition of $\mathrm{Ru}(\mathrm{COD})(\mathrm{COT})$ (COD: 1,5-cyclooctadiene, COT: 1,3,5- cyclooctatriene) in mild conditions $\left(20{ }^{\circ} \mathrm{C}, 3\right.$ bar $\left.\mathrm{H}_{2}\right)$ and in presence of amines, alcohols or thiols as stabilizers [12,13]. To our knowledge, these particles are not stable under treatment at high temperature since heat treatment leads to drastic sintering of the particles [14].

We recently demonstrated that Ru nanoparticles of about $2.4 \mathrm{~nm}$ in diameter, covered by octylsilane fragments can be prepared [15] by the Surface Organo-Metallic Chemistry on Metals route [16], using $\mathrm{Ru}(\mathrm{COD})(\mathrm{COT})$ as precursor and octylsilane $\left(\mathrm{H}_{3} \mathrm{Si}-\mathrm{C} 8\right)$ as stabilizer. In our case, the presence of grafted $\equiv \mathrm{Si}-\mathrm{C} 8$ fragments on the su face of the particles was evidenced by IR spectroscopy and solid state ${ }^{13} \mathrm{C}$ CP-MAS NMR. This is different from the organosilane functionalized gold nanocrystal prepared by Fan et al. [17] where the silane function is in the external layer of the micelle. The created Ru-Si bond is very strong and can present advantages forming a stable catalyst with a defined hydrophobic layer (alkyl chain) in order to orga ize the substrates in a selective way.

\section{Results and discussion}

Using the procedure already described [15] and starting with a $\mathrm{H}_{3} \mathrm{Si}-\mathrm{C} 8 / \mathrm{Ru}(\mathrm{COD})(\mathrm{COT})$ initial ratio varying from 0.2 to 2.0, Ru particles with diameter $(d)$ varying from 1.6 to $3.2 \mathrm{~nm}$ were obtained (Tab. 1 ). The dispersion of the particles ( $D=\mathrm{Rus} / \mathrm{Ru}$, where Rus and Ru are the number of surface ruthenium atoms and the total number of atoms) were calculated assuming a cubooctahedral shape. It must be point out that the results ofboth elemental analyses (which correspond to macroscopic values) and EDX (which gives the amount of each element on a given particle or on a small number of particles) are comparable, showing that the samples are highly homogeneous. An average stoichiometry vs. total ruthenium atoms of the particles $\mathrm{Ru}[\mathrm{Si}(n-\mathrm{C} 8) x] y$ can be given using the results of elemental analysis. The silicon to total ruthenium ratio of the particles 
Table 1: Particles sizes and dispersions deduced from TEM data and results of elemental analysis (E.A.) and EDX measurements for Ru/Si-C8 particles.

\begin{tabular}{|c|c|c|c|c|}
\hline Initial $\mathrm{Si} / \mathrm{Ru}$ ratio & 0.2 & 0.5 & 1.0 & 2.0 \\
\hline$d^{2}(\mathrm{~nm})$ & 1.6 & 1.6 & 2.3 & $\sim 3$ \\
\hline$D^{b}\left(\mathrm{Ru}_{2} / \mathrm{Ru}\right)$ & 0.61 & 0.59 & 0.48 & n.d. \\
\hline $\mathrm{Ru}(\% \mathrm{w})$ E.A. ${ }^{c}$ & 69.5 & 70.0 & $68.4-68.6$ & 70.9 \\
\hline Ru $(\% w)$ EDX & 69.0 & 71.0 & 69.0 & 83.0 \\
\hline $\mathrm{Si}(\% \mathrm{w})$ E.A. & 5.3 & 11.2 & $9.2-10.4$ & 14.3 \\
\hline $\mathrm{Si}(\% \mathrm{w}) \mathrm{EDX}$. & 5.2 & 11.0 & 11.0 & 14.0 \\
\hline C (\% w) E.A. & 4.1 & 11.5 & $19.5-24.4$ & 32.8 \\
\hline $\mathrm{Si} / \mathrm{Ru}$ (average) & 0.28 & 0.57 & 0.54 & 0.67 \\
\hline$x=\mathrm{C} 8 / \mathrm{Si}$ (E.A.) & 0.22 & 0.30 & $0.62-0.68$ & 0.67 \\
\hline Stoichiometry vs. Ru & $\mathrm{Ru}\left[\mathrm{Si}(\mathrm{C} 8)_{0.22}\right]_{0.28}$ & $\mathrm{Ru}\left[\mathrm{Si}(\mathrm{C} 8)_{0.90}\right]_{0.87}$ & $\mathrm{Ru}\left[\mathrm{Si}(\mathrm{CB})_{0 . \approx 5}\right]_{0.84}$ & $\mathrm{Ru}\left[\mathrm{Si}(\mathrm{C} 8)_{0.67}\right]_{0.67}$ \\
\hline $\mathrm{Si} / \mathrm{Ru}$, & 0.46 & 0.97 & 1.13 & - \\
\hline
\end{tabular}

a Scanning transmission electron microscopy with EDX was carried out at the Institut de Recherches sur la Catalyse, CNRS, Villeurbanne, France, using JEOL $100 \mathrm{CX}$ electron microscope. The mean particle diameter (d) was determined by obearvation of more than 200 particles from 5 TEM pictures.

${ }^{b}$ Dispersion $(D)$ of the sample is the ratio between number of surface $\mathrm{Ru}$ atoms $\mathrm{Ru}_{\mathrm{x}}$ and the total number of atoms in a particle of a diameter $(d)$.

${ }^{c}$ Elemental analyses were performed at the Laboratoire de Synthèse et Électrosynthèse Organométalliques, UMR 5188 CNRS, Dijon, France for carbon and hydrogen and at the Service Central d'Analyse, Département Analyse Élémentaire, CNRS, Vernaison, France for ruthenium and silicium. All sample preparations were realized under argon and the elemental analyses were done without contact with air.

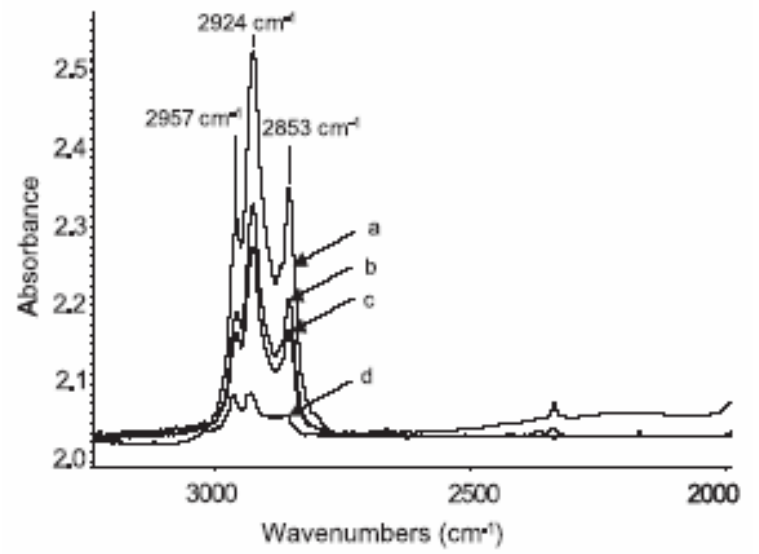

Figure 1: Infra red spectra of Ru/Si-C8 particles stabilized with (a) 2.0, (b) 1.0, (c) 0.5 and (d) 0.2 eq. of octylsilane.

indicates that up to an initial $\mathrm{Si} / \mathrm{Ru}$ ratio of ca. 0.6 all silicon has been "chemisorbed" on the particles. Increasing the amount of octylsilane does not result in the incorporation of a higher amount of silicon, leading to the conclusion that for initial $\mathrm{Si} / \mathrm{Ru}$ ratio greater than ca. 0.6 , the excess of silane which was not grafted is removed by washing.

Infrared spectroscopy of the dried solids, embedded in $\mathrm{KBr}$, following the procedure already described [15] are represented in Figure 1.

These spectra demonstrate that Si-H vibrations, expected at $2100 \mathrm{~cm}^{-1}$ are totally absent whatever the initial $\mathrm{Si} / \mathrm{Ru}$ ratio. We can then conclude that all silicon hydrides had reacted during the grafting reaction of the silane on the metal particle, in complete accordance with Hostetler et al. [18] who found that primary organosilanes react readily with transition metal surfaces at temperature below $-20 \circ \mathrm{C}$ with formation of surface-bound silylines. Since $v(\mathrm{CH} 2)$ and $v\left(\mathrm{CH}_{3}\right)$ vibrations are still observed in the 2800-3000 $\mathrm{cm}^{-1}$ region, the presence of $\equiv \mathrm{Si}$-C8 fragments on the sur- face is then evidenced, as demonstrate in the previous work [15].

Solid state NMR data are in agreement with this conclusion. If one excepts the sample with the lowest silane content, for which the signal to noise ratio is very bad (due to the low amount of carbon), all spectra show four wellresolved peaks at 32.9, 29.7, 23.1 and $14.4 \mathrm{ppm}$. The signal at $14.4 \mathrm{ppm}$ can be attributed to the terminal methyl group of the octyl ligand, those at 27.3 and $29.7 \mathrm{ppm}$ to the $\mathrm{C} \beta$ and $\mathrm{C} \gamma$ carbon atoms and that at 32.9 to the methylene groups of the chain. Only the $\mathrm{C} \alpha$ signal, expected at 6.2 $\mathrm{ppm}$ is missing due to the proximity to the metal surface in accordance with the literature [12].

From these results, we can expect at the surface of the ruthenium particles the presence of only two species, naked silicon atoms that is silicon for which the Si-carbon chain has been cleaved and $\equiv \mathrm{Si}$-C8 fragments. Assuming that all silicon atoms are located on the surface of the ruthenium particles, the value corresponding to $\mathrm{Si} / \mathrm{Rus}$ can be given, almost for starting $\mathrm{Si} / \mathrm{Ru}$ ratio of $0.2 ; 0.5$ and 1.0 (Tab. 1). It seems that the $\mathrm{Si} / \mathrm{Rus}$ value increases with the initial $\mathrm{Si} / \mathrm{Ru}$, up to a maximum of about one, which corresponds to a full coverage of the metallic surface. As seen in Table 1 , the $x$ value $(\mathrm{C} 8 / \mathrm{Si})$ increases with the $y$ ( $\mathrm{Si} / \mathrm{Rus}$ ) value. This means that the hydrogenolysis of the Si-C8 bond is deeper at low coverage of the ruthenium surface by $\mathrm{Si}$. This result is in perfect agreement with previous results obtained by reaction of tetrabutyl tin $\left(\mathrm{Sn}\left(n-\mathrm{C}_{4} \mathrm{H}_{9}\right)_{4}\right)$ on $\mathrm{Rh} / \mathrm{SiO}_{2}$ or $\mathrm{Pt} / \mathrm{SiO}_{2}$ catalysts $[19,20]$ and could be interpreted by a "poisoning" effect of the Si grafted on the metallic surface toward hydrogenolysis of the Si-C8 bond.

These particles (starting with $\mathrm{Si} / \mathrm{Ru}=1$ ) were treated, under flowing $\mathrm{H}_{2}$ or $\mathrm{N}_{2}$, in a reaction chamber designed for in situ XRD analysis. The temperature program for both cases was the following: increasing of the temperature from room temperature to $500{ }^{\circ} \mathrm{C}$ with $0.5{ }^{\circ} \mathrm{C} / \mathrm{min}$, then 3 hours at $500{ }^{\circ} \mathrm{C}$. The XRD patterns of the sample treated at $25{ }^{\circ} \mathrm{C}$ under $\mathrm{N}_{2}$ (Fig. 2) show only a broad band of very small 
intensity, which is compatible with very small Ru particles, in accordance with TEM analysis (Fig. 3). After treatment

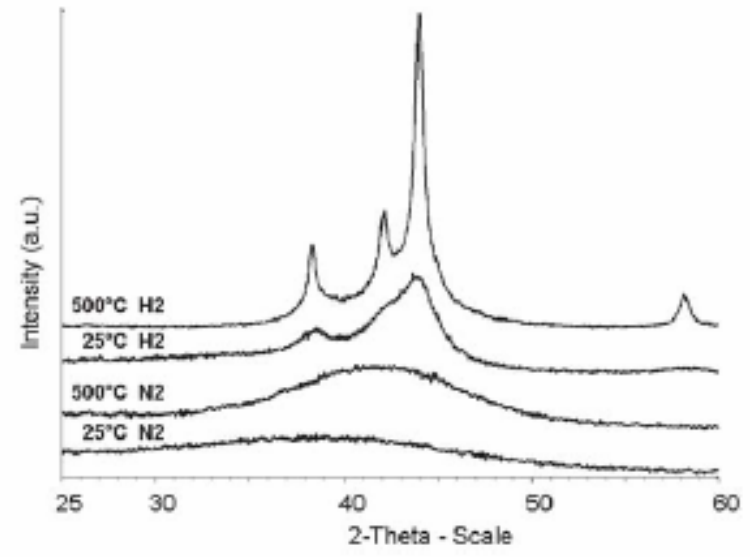

Figure 2: XRD pattern of Ru particles after heat treatment under $\mathrm{N}_{2}$ or $\mathrm{H}_{2}$ at $25^{\circ} \mathrm{C}$ or $500{ }^{\circ} \mathrm{C}$.

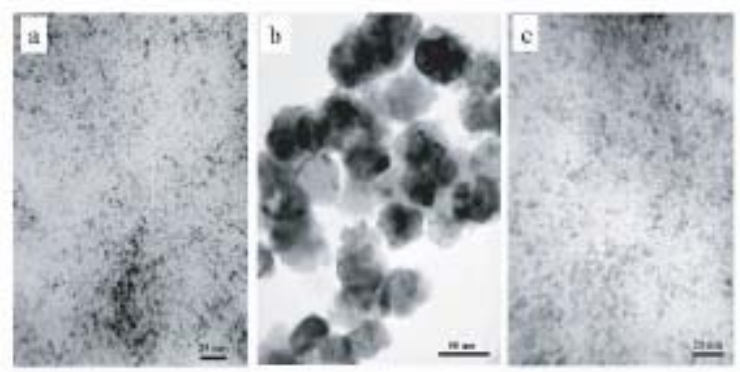

Figure 3: TEM images of Ru particles, initial material (a), treated at $500{ }^{\circ} \mathrm{C}$ under flowing $\mathrm{H}_{2}$ (b) or $\mathrm{N}_{2}$ (c).

under flowing $\mathrm{H}_{2}$ up to $500{ }^{\circ} \mathrm{C}$, relatively sharp peaks corresponding to the $\mathrm{Ru}$ crystallographic structure were observed, showing the sintering of the particles. Even at $25^{\circ} \mathrm{C}$ under $\mathrm{H}_{2}$ one can already observe a small increase in size compared to the original sample. In the contrary, treatment under flowing $\mathrm{N}_{2}$ leads to a very small change in the XRD pattern, evidencing a small evolution of the size of the $\mathrm{Ru}$ nanoparticles. This unexpected result was confirmed by TEM analysis of the samples after treatment. As shown in Figure 3, very large Ru particles of about $50 \mathrm{~nm}$ are obtained after treatment in $\mathrm{H}_{2}$ while almost unchanged particles were observed after treatment under neutral atmosphere.

\section{References}

1. H. Bönnemann, G. Braun, W. Brijoux, A.S. Tilling, K. Seevogel, K. Siepen, J. Organomet. Chem. 520, 143 (1996)

2. H. B“onnemann, R.M. Richards, Eur. J. Inorg. Chem. 10, 2455 (2001)

3. A.C. Templeton, W.P. Wuelfing, R.W. Murray, Acc. Chem. Research 33, 27 (2000)

4. G. Schmid, B. Corain, Eur. J. Inorg. Chem. 17, 3081 (2003)

5. M.-C. Daniel, D. Astruc, Chem. Rev. 104, 293 (2004)

6. G. Schmid, V. Maihack, F. Lantermann, S. Peschel, J. Chem. Soc., Dalton Transactions: Inorg. Chem. 5, 589 (1996)
It is obvious that under flowing $\mathrm{H}_{2}$, a drastic sintering of the particles occurs although under $\mathrm{N}_{2}$, a protecting layer is formed on the metallic surface which inhibits the coalescence of the particles, even at temperature as high as $500{ }^{\circ} \mathrm{C}$.

\section{Conclusions}

In conclusion, it has been demonstrated that small ruthenium nanoparticles with average diameter ranging from 1.6 to $2.3 \mathrm{~nm}$ can be obtained using various octylsilane/ $\mathrm{Ru}(\mathrm{COD})(\mathrm{COT})$ ratios (0.2, 0.5, 1.0 and 2.0). These small metallic particles were characterized by elemental analysis, TEM, IR and solid state ${ }^{13} \mathrm{C}$ MAS NMR. It was observed that the smallest particles were obtained for the lowest $\mathrm{Si} / \mathrm{Ru}$ ratio (0.2). Two species exist on the surface of the particles, naked silicon atoms and $\equiv \mathrm{Si}-\mathrm{C} 8$ fragments. Naked silicon atoms are predominant for initial $\mathrm{Si} / \mathrm{Ru}$ ratio of 0.2 and 0.5 , while for higher coverage the $\equiv \mathrm{Si}$-C8 fragments are majority. These nanoparticles exhibit unexpected stability toward heat treatment under neutral atmosphere. Under these conditions, a protecting layer is formed on the metallic surface which inhibits the coalescence of the particles, even at temperature as high as $500{ }^{\circ} \mathrm{C}$ as shown by in situ XRD measurements.

\section{Acknowledgement}

This work was supported by the DAAD.
7. J. Fink, C.J. Kiely, D. Bethell, D.J. Schiffrin, Chem. Mat. 10, 922 (1998)

8. F. Dassenoy, K. Philippot, C. Amiens, M.J. Casanove, B. Chaudret, New J. Chem. 22, 703 (1998)

9. A. Badia, W. Gao, S. Singh, L. Demers, L. Cuccia, L. Reven, Langmuir 12, 1262 (1996)

10. R.H. Terrill, T.A. Postlethwaite, C.-H. Chen, C.-D. Poon, A. Terzis, A. Chen, J.E. Hutchinson, M.R. Clark, G. Wignall, J.D. Londono, R. Superfine, M. Falvo, C.S. Johnson, E.T. Samulski, R.W. Murray, J. Am. Chem. Soc. 117, 12537 (1995) 
11. N. Chakroune, G. Viau, S. Ammar, L. Poul, D. Veautier, M.M. Chehimi, C. Mangeney, F. Villain, F. Fi'evet, Langmuir 21, 6788 (2005)

12. C. Pan, K. Pelzer, K. Philippot, B. Chaudret, F. Dassenoy, P.M. Lecante, J. Casanove, J. Am. Chem. Soc. 123, 7584 (2001)

13. K. Pelzer, O. Vidoni, K. Philippot, B. Chaudret, V. Colli`ere, Adv. Funct. Mater. 13, 118 (2003)

14. M. Jos`e-Yacaman, C. Gutierrez-Wing, M. Miki, D.-Q. Yang, K.N. Piyakis, E. Sacher, J. Phys. Chem. B 109, 9703 (2005)

15. K. Pelzer, B. Laleu, F. Lefebvre, K. Philippot, B. Chaudret, J.P. Candy, J.M. Basset, Chem. Mat. 16, 4937 (2004)

16. J.P. Candy, B. Didillon, E.L. Smith, T.B. Shay, J.M. Basset, J. Mol. Catal. 86, 179 (1994)
17. H. Fan, Z. Chen, C.J. Brinker, J. Clawson, T. Alam, J. Am. Chem. Soc. 127, 13746 (2005)

18. M.J. Hosteler, R.G. Nuzzo, G.S. Girolami, J. Am. Chem. Soc. 116, 11608 (1994)

19. F.Z. Bentahar, F. Bayard, J.P. Candy, J.M. Basset, in Fundamental and Applied Aspects of Chemically Modified Surfaces, edited by J.P. Blitz, C.B. Little (The Royal Society of Chemistry 1999), p. 235

20. O.A. Ferretti, C. Lucas, J.P. Candy, J.M. Basset, B. Didillon, F. Le Peltier, J. Mol. Catal. 103, 125 (1995) 